\title{
Significant cardiac disease complicating Graves' disease in previously healthy young adults
}

\author{
J K Witczak1,2, N Ubaysekara², R Ravindran², S Rice1, Z Yousef ${ }^{3}$ and L D Premawardhana² \\ 1Section of Endocrinology, Department of Medicine, Prince Phillip Hospital, ${ }^{2}$ Centre for Endocrine and Diabetes \\ Sciences, University Hospital of Wales, Heath Park, Cardiff, UK, and ${ }^{3}$ Department of Cardiology, University Hospital of \\ Wales, Heath Park, Cardiff, UK
}

Correspondence should be addressed to J K Witczak

Email

justyna.witczak@wales.nhs.uk

\section{Summary}

Graves' disease is associated with tachydysrythmia, cardiac ischaemia and cardiomyopathy - all uncommon in young adults without previous cardiac disease. We present three young individuals who developed cardiac complications after periods of uncontrolled Graves' disease. Subject 1: A 34-year-old female had severe thyrotoxic symptoms for weeks. Investigations showed fT4: 98.4 (11-25 pmol/L), fT3: 46.9 (3.1-6.8 pmol/L), TSH <0.01 (0.27-4.2 mU/L) and thyrotrophin receptor antibody (TRAb): 34.8 ( $<0.9 \mathrm{U} / / \mathrm{I})$. She had appropriate treatment but several weeks later she became breathless despite improving thyroid function. Echocardiography showed a pericardial effusion of $2.9 \mathrm{~cm}$. She responded well to steroids and NSAIDs but developed active severe Graves' orbitopathy after early total thyroidectomy. Subject 2: A 28-year-old male developed thyrotoxic symptoms (fT4: $38 \mathrm{pmol} / \mathrm{L}, \mathrm{fT} 3: 13.9 \mathrm{pmol} / \mathrm{L}, \mathrm{TSH}<0.01$ (for over 6 months) and TRAb: $9.3 \mathrm{U} / \mathrm{L}$ ). One month after starting carbimazole, he developed acute heart failure (HF) due to severe dilated cardiomyopathy - EF 10-15\%. He partially recovered after treatment - EF $28 \%$ and had early radioiodine treatment. Subject 3: A 42-year-old woman who had been thyrotoxic for several months (fT4: 54.3; fT3 >46.1; TSH <0.01; TRAb: 4.5) developed atrial fibrillation (AF) and heart failure. Echocardiography showed cardiomegaly - EF $29 \%$. She maintains sinus rhythm following early total thyroidectomy (EF 50\%). Significant cardiac complications may occur in previously fit young adults, who have had uncontrolled Graves' disease for weeks to months. Cardiac function recovers in the majority, but early definitive treatment should be discussed to avoid Graves' disease relapse and further cardiac decompensation.

\section{Learning points:}

- Cardiac complications of Graves' disease are uncommon in young adults without previous cardiac disease.

- These complications may however occur if Graves' disease had been poorly controlled for several weeks or months prior to presentation.

- Persistent symptoms after adequate control should alert clinicians to the possibility of cardiac disease.

- Specific treatment of Graves' disease and appropriate cardiac intervention results in complete recovery in the majority and carries a good prognosis.

- Early definitive treatment should be offered to them to prevent cardiac decompensation at times of further relapse. 


\section{Background}

Thyrotoxicosis causes well-recognised cardiac effects in the short term - increased ventricular rate, stroke volume, improved left ventricular systolic function and relaxation time. These changes are mediated through genomic and non-genomic effects of thyroid hormones. However, in the longer term and if left untreated Graves' disease, the commonest form of thyrotoxicosis, leads to increased cardiovascular morbidity and death (1). Heart failure estimated to affect $16 \%$ in overt hyperthyroidism contributes to this increased risk of cardiovascular morbidity even in those without pre-existing cardiac disease (2).

Thyroid hormones have direct effects on the myocardium (mediated through triiodothyronine - fT3), the systemic vasculature and the autonomic nervous system (3). Supraventricular tachydysrhythmias, heart failure, cardiomyopathy, pulmonary hypertension and pericardial effusion are recognized cardiac complications of thyrotoxicosis $(4,5)$. The risks of these cardiovascular complications developing are higher in the middle aged and elderly and in those with pre-existing cardiac disease. However, there are increasing reports of these occurring in young adults without previous cardiac disease (4). The majority of these subjects (usually untreated or partially treated for months) recover completely after Graves' disease treatment and cardiac intervention. Reversible dilated cardiomyopathy, pericardial effusion and heart failure amongst others have been previously reported in young patients with Graves' disease $(4,5,6)$.

We present three young subjects without previous cardiac disease, who developed major cardiac complications of Graves' disease following significant periods of uncontrolled thyrotoxicosis. We highlight the importance of diagnosing cardiac disease in this group of young and previously healthy individuals, particularly if they have persistent symptoms despite adequate control of Graves' disease. We also highlight the reversible nature of their cardiac disease when Graves' disease is controlled.

\section{Case presentation}

\section{Subject 1}

A 34-year-old previously healthy female presented with breathlessness, palpitations, tremors and agitation of several weeks' duration. She smoked ten cigarettes/day but had no other significant social or family history. On examination her temperature was $38.2^{\circ} \mathrm{C}$, pulse $145 / \mathrm{min}$ and regular and BP 146/86 $\mathrm{mmHg}$. She was sweating profusely, agitated and had tremors of her hands. There was a smooth, symmetrically enlarged goitre but no bruit over it. She also had mild inactive Graves' orbitopathy.

\section{Subject 2}

A 28-year-old previously fit male kitchen worker, presented with weight loss (one stone in 6 months), palpitations, sweating and diarrhoea with no symptoms of Graves' orbitopathy. He did not smoke and consumed very little alcohol. His past medical and social history were unremarkable, but a cousin had thyrotoxicosis. He had documented ongoing biochemical thyrotoxicosis for the past few months. He was initially given carbimazole when Graves' disease was first diagnosed but had discontinued treatment for unknown reasons after only a few weeks and presented again a few months later. Clinically he appeared thyrotoxic with a regular pulse of $96 / \mathrm{min}$, BP $111 / 79 \mathrm{mmHg}$, tremors of the hands and a smooth, symmetrical goitre with a bruit heard over it.

\section{Subject 3}

A 42-year-old woman (ex-smoker who did not consume alcohol) with previously normal cardiovascular health, presented acutely with palpitations, breathlessness and leg swelling. She had been treated 3 years earlier for Graves' disease but had an untreated relapse for at least 2 months before presentation. She had no significant family medical history. Clinically she was found to be in atrial fibrillation with a ventricular rate of $120 / \mathrm{min}$, BP $136 / 81 \mathrm{mmHg}$ and was in heart failure.

\section{Investigations}

\section{Subject 1}

\section{Initial investigations}

On admission her free thyroxine (fT4) was 98.4 (11-25 pmol/L), fT3: 46.9 (3.1-6.8 pmol/L), TSH $<0.01(0.27-4.2$ $\mathrm{mU} / \mathrm{L})$ and thyrotrophin receptor antibody (TRAb): 34.8 $(<0.9 \mathrm{U} / \mathrm{L})$.

\section{At time of decompensation}

fT4: 27.8; fT3: 12.8; Chest radiography revealed cardiomegaly, and an echocardiogram confirmed cardiomegaly with a moderate pericardial effusion (2.9 $\mathrm{cm}$ ) and an ejection fraction (EF) of $>55 \%$. Other causes for a pericardial effusion were excluded by appropriate investigations. 


\section{Subject 2}

Initial investigations

His fT4 was 38 (9-19.1 pmol/L), fT3: 13.9 (2.6-5.7 pmol/L), TSH $<0.01$ and TRAb: 9.3 .

\section{At time of decompensation}

Echocardiography revealed features of severe dilated cardiomyopathy (DCM) with a left ventricular EF of $12 \%$ and spherical heart geometry (Fig. 1). Comprehensive investigations (including coronary angiography, cardiac MRI and cardiomyopathy screen) ruled out other causes for DCM. EF partially recovered to $28 \%$ after definitive treatment of Graves' disease.

\section{Subject 3}

Her thyroid tests showed fT4: $54.3 \mathrm{pmol} / \mathrm{L}$; fT3 $>46.1$ pmol/L; TSH $<0.01$ and TRAb: 4.5 . A chest X'ray showed cardiomegaly and hilar prominence. Echocardiography showed cardiomegaly, impairment of LV function with an EF of $29 \%$ and a small pericardial effusion $(0.42 \mathrm{~cm})$ with spherical heart geometry. Myocardial perfusion scans did not show inducible ischemia.

\section{Treatment}

\section{Subject 1}

A thyroid storm was diagnosed (Wartofsky-Burch score $45)$, and she was given carbimazole (60 $\mathrm{mg}$ stat, then 40 $\mathrm{mg}$ per day thereafter), propranolol $80 \mathrm{mg}$ stat and $60 \mathrm{mg}$ TDS thereafter, steroids (IV hydrocortisone $200 \mathrm{mg}$ stat, $100 \mathrm{mg}$ IV TDS on day 2, $50 \mathrm{mg}$ IV TDS on day 3, switched to oral prednisolone $30 \mathrm{mg}$ OD on day 4) and antibiotics (Co-amoxiclav initially $1.2 \mathrm{~g}$ IVD TDS switched to 625 $\mathrm{mg}$ TDS orally on day 3 and clarithromycin $500 \mathrm{mg}$ orally BD for 7 days total) with i.v. fluids. Prednisolone was increased to $40 \mathrm{mg}$ OD when she presented with pericardial effusion and reduced gradually by $5 \mathrm{mg} /$ week over 8 weeks. She was also given non-steroidal agents (ibuprofen $600 \mathrm{mg}$ TDS for 10 days). Subsequently, she underwent a total thyroidectomy and currently has stable thyroid function on thyroxine replacement therapy - 100

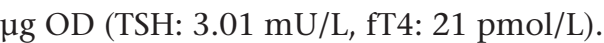

\section{Subject 2}

At the time of initial diagnosis, he was given carbimazole $15 \mathrm{mg}$ per day which he stopped after a few weeks without a clear reason. When he presented with uncontrolled

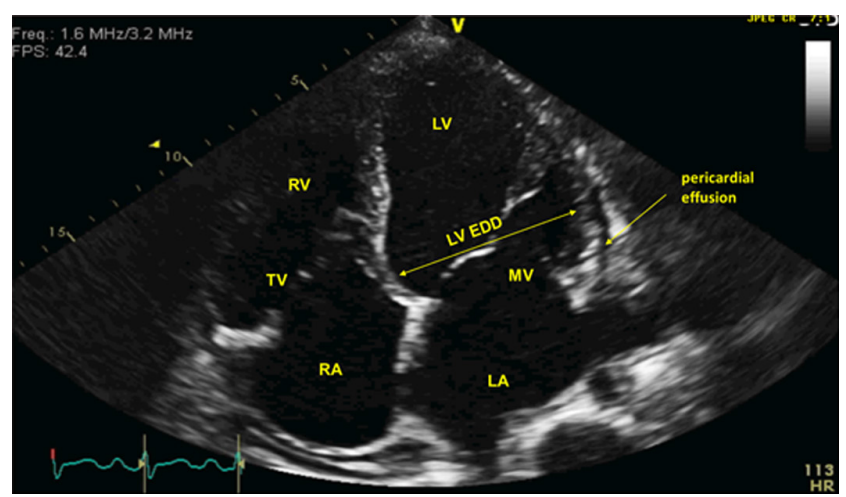

Figure 1

The long axis four chamber echocardiographic view of the heart shows biventricular dilatation (RV EDD: $5.5 \mathrm{~cm}$, LV EDD: $6.6 \mathrm{~cm}$ ) with severe LV systolic dysfunction (EF 10-15\%), moderate-severe functional mitral regurgitation and no wall motion abnormalities. These features are consistent with a non-ischaemic dilated cardiomyopathy. EDD (enddiastolic diameter): $6 \mathrm{~cm}$, ESD (end-systolic diameter): $4.8 \mathrm{~cm}$, ESV (end systolic volume): $201 \mathrm{~mL}$, EDV (end-diastolic volume): $261 \mathrm{~mL}$, IVS (intraventricular septum wall thickness): $0.7 \mathrm{~cm}, \mathrm{PW}$ (posterior wall thickness): $0.9 \mathrm{~cm}$, RWT (LV relative wall thickness): $0.3 \mathrm{~cm}$, calculated EF 23\%, LA volume $62 \mathrm{~mL}$, LV wall mass $186 \mathrm{~g}$, LV mass index $96 \mathrm{~g} / \mathrm{m}^{2}$, $P A P=$ no $T R$ jet. RV, right ventricle; LV, left ventricle; EDD, end-diastolic diameter; EF, ejection fraction.

thyrotoxicosis, he was given carbimazole (20 mg BD) and propranolol (40 mg BD) which he could not tolerate. When dilated cardiomyopathy and heart failure developed a few weeks later, lisinopril $2.5 \mathrm{mg}$ OD, bumetanide $1 \mathrm{md} \mathrm{BD}$, eplerenone $25 \mathrm{mg} \mathrm{OD}$ and ivabradine $5 \mathrm{mg} \mathrm{BD}$ were also given. He had early radioiodine (RAI) treatment (I131 at a dose of $555 \mathrm{MBq}$ ).

\section{Subject 3}

She was commenced on bisoprolol $10 \mathrm{mg}$ OD, digoxin $125 \mu \mathrm{g}$ OD, propylthiouracil $100 \mathrm{mg}$ BD (carbimazole intolerant - rash), furosemide $40 \mathrm{mg}$ OD and ramipril $1.25 \mathrm{mg}$ OD. We decided not to anticoagulate her in view of a microcytic anaemia and severe menorrhagia which was being investigated by the gynaecologists. Following a period of stability, she had early total thyroidectomy.

\section{Outcome and follow-up}

\section{Subject 1}

She responded well to steroids and non-steroidal agents, and two months later a repeat echocardiogram showed complete resolution of the pericardial effusion. Her thyroid function normalized on carbimazole, and she underwent a total thyroidectomy and currently has stable thyroid function on thyroxine replacement. However, 
3 months after surgery she developed active severe Graves' orbitopathy requiring high dose steroids and orbital radiotherapy 20 Gy in ten fractions. Her eye symptoms continue to improve slowly on reducing doses of steroids.

\section{Subject 2}

He had early radioiodine (RAI) treatment and is now stable on thyroxine replacement therapy. His ejection fraction partially recovered to $35 \%$ after definitive treatment of Graves' disease, and his heart geometry is now ellipsoid. He maintains cardiovascular stability on medication. He is currently on $100 \mu \mathrm{g}$ OD of levothyroxine with stable thyroid function (TSH: $3.19 \mathrm{mU} / \mathrm{L}$, fT4: $16.2 \mathrm{pmol} / \mathrm{L}$ ).

\section{Subject 3}

Following treatment, her ejection fraction improved to $40-45 \%$ and she has ellipsoid heart geometry. She had early total thyroidectomy and continues to be well on thyroxine replacement. She has also been in persistent sinus rhythm with recovery of her EF to $50 \%$ on the previously mentioned medication. She remains euthyroid on $150 \mu \mathrm{g}$ of levothyroxine (TSH: $3.58 \mathrm{mU} / \mathrm{L}$, fT4: $13.4 \mathrm{pmol} / \mathrm{L}$ ).

\section{Discussion}

We have described three young subjects without previously known cardiac disease, who presented with well recognized but uncommon cardiac complications of Graves' disease in this age group. Thyroid dysfunction with raised fT3 and fT4 had been present and untreated or partially treated for several weeks to months prior to presentation in all of them. All three patients had substantial recovery of cardiac function after effective control of Graves' disease and cardiac intervention.

Thyroid hormones exert their effects on cardiac myocytes, vascular smooth muscle and vascular endothelium by both genomic (fT3) and non-genomic (fT3 and fT4) actions (7). While these mechanisms control effects on heart rate and rhythm, other effects such as changes to autonomic function may also contribute to cardiovascular actions (8). These effects of thyroid hormones are mediated through activation of genes controlling cardiac muscle function and chronotropy (8). Cardiac contractility improves in the short term, and in the long-term cardiac mass increases. However, if thyrotoxicosis is prolonged or severe, heart failure may develop often when a tachydysrhythmia such as atrial fibrillation (AF) supervenes. Increasing age, pre-existing coronary and valvular heart disease are risk factors for AF and its complications. But it is now being increasingly recognized that Graves' disease causes significant cardiac morbidity and mortality even in young individuals who have no previously known cardiac disease $(4,9)$. None of our subjects had previous heart disease and at presentation had no clinically apparent vascular risk factors or comorbidities other than Graves' disease. It is noteworthy that they also had untreated or partially treated Graves' disease for several weeks to months before presentation. Despite previously normal cardiac function, it is possible that sub-optimally treated Graves' disease over several months places physiological burdens even on relatively youthful cardiovascular systems causing acute decompensation.

Pericardial effusion (PE) complicating Graves' disease is relatively uncommon -7 of 12 case reports of pericardial effusion in subjects with thyrotoxicosis had Graves' disease (10). Both serous and bloody effusions have been reported. Two subjects were reported to require pericardiocentesis for cardiac tamponade (10). None of these subjects had previous cardiac disease. Although the exact mechanism of pericardial effusion in Graves' disease is not known, immune mechanisms are increasingly thought to be relevant. Our Subject 1 had a pericardial effusion complicating Graves' disease which developed a few weeks after starting treatment. A new onset of breathlessness at a time when thyroid function was improving after a thyroid storm alerted physicians to this uncommon cause for her symptoms. Her effusion responded to standard therapy and there was full cardiac recovery.

Severe cardiomyopathy in adults with hyperthyroidsm is rare - estimated to occur only in about $5.8 \%(11,12)$. But of them, only $<1 \%$ develop dilated cardiomyopathy with LV impairment. Although most recover, some deaths have been reported. The exact mechanism of dilated cardiomyopathy in Graves' disease is uncertain, and prolonged uncontrolled hyperthyroidism and autoimmunity have been postulated as being causative (13). Tachycardia related cardiomyopathy (TCM) may also complicate Graves' disease, and in a recent study on TCM, LV dysfunction did not normalise despite adequate rhythm and rate control, implying a possible underlying cardiac abnormality before the onset of the tachycardia. Our Subject 2 had a likely tachycardia-related cardiomyopathy presenting as decompensated dilated cardiomyopathy for which no obvious cause other than Graves' disease was found. His cardiac recovery was 
partial (EF improving to 28\%) despite adequate cardiac and endocrine control. We can only speculate whether an underlying cardiac abnormality was present in him prior to the development of Graves' disease.

There is an increased prevalence of AF in those with hyperthyroidism compared to the general population (10$15 \%$ vs $0.5 \%$ ) and the prevalence is higher in those with coronary or valvular heart disease and HF. The development of $\mathrm{AF}$ in thyrotoxicosis is related to multiple actions of fT3 - an increase in systolic and diastolic depolarisation, decrease in the duration of the action potential and a decrease in the refractory period of the atrium and the atrio-ventricular node. The role of the pulmonary veins has also been recognised. The risk of ischaemic stroke is increased in those with AF complicating hyperthyroidism. The view that hyperthyroidism is a 'procoagulant state' has also to be considered when assessing the risk of ischaemic stroke in this condition. The role of the reported increase in fibrinogen, factor $\mathrm{X}$ and Von Willebrand antigen levels are currently only speculative. However, there have been no clinical trials assessing the benefit of anticoagulation in these individuals (14). The guidance with regard to anticoagulation in AF complicating Graves' disease is confusing. The American College of Chest Physicians recommend anticoagulation only in those who qualify on the basis of a standard CHA2DS2VASC assessment, as they conclude that hyperthyroidism is not an independent risk factor for thrombo-embolic stroke (15). However, the American College of Cardiology recommends anticoagulation in hyperthyroidism regardless of CHA2DS2-VASC score as they consider that hyperthyroidism is indeed an independent risk factor for stroke (16). If AF persists, cardioversion should be considered, and ablation should be considered for those with recurrent AF (17). As discussed, under investigation by the gynaecologists, we elected not to anticoagulate subject 3 because of severe menorrhagia complicated by a microcytic anaemia.

\section{Conclusions}

We have demonstrated that significant cardiac complications of Graves' disease (pericardial effusion, dilated cardiomyopathy and rate related cardiomyopathy and AF causing heart failure) may occur in previously fit young patients without cardiac disease. All of them had partially treated or untreated Graves' disease for several weeks to months. It is therefore important to exclude Graves' disease-related cardiac disease in those developing significant cardiorespiratory symptoms inconsistent with their thyroid status and under appropriate clinical circumstances. The majority of patients respond well to thionamides and specific cardiac intervention with complete or partial reversal of cardiac abnormalities (18), but definitive treatment should be discussed early to avoid Graves' disease relapse and a potential recurrence of cardiac decompensation (19).

\section{Declaration of interest}

The authors declare that there is no conflict of interest that could be perceived as prejudicing the impartiality of this case report.

\section{Funding}

This research did not receive any specific grant from any funding agency in the public, commercial or not-for-profit sector.

\section{Patient consent}

Written informed consent has been obtained from all three patients for the publication of this report and images

\section{Author contribution statement}

All authors contributed to writing of this manuscript; J W, N U and L P prepared its current form for submission; J W and S R were involved in the care of case $1 ;$ J W, R R, Z Y and L P were involved in the care of case 2 and $R R, Z Y$ and $L P$ were involved in the care of case 3 .

\section{References}

1 Brandt F, Green A, Hegedüs L \& Brix TH. A critical review and meta-analysis of the association between overt hyperthyroidism and mortality. European Journal of Endocrinology 2011165 491-497. (https://doi.org/10.1530/EJE-11-0299)

2 Biondi B. Mechanisms in Endocrinology: heart failure and thyroid dysfunction. European Journal of Endocrinology 2012167 609-618. (https://doi.org/10.1530/EJE-12-0627)

3 Polikar R, Burger AG, Scherrer U \& Nicod P. The thyroid and the heart. Circulation 199387 1435-1441. (https://doi.org/10.1161/01. CIR.87.5.1435)

4 Biondi B \& Kahaly G.J. Cardiovascular involvement in patients with different causes of hyperthyroidism. Nature Reviews Endocrinology 20106 431-443. (https://doi.org/10.1038/nrendo.2010.105)

5 Clarke NRA, Banning AP, Gwilt DJ \& Scott AR. Pericardial disease associated with Grave's thyrotoxicosis. Quarterly Journal of Medicine 200295 188-189. (https://doi.org/10.1093/qjmed/95.3.188)

6 Moustaghfir A, Kharchafi A, Belmejdoub G, Chaari J, Ghafir D, Had A, Ohayon V \& Archane MI. Cardiothyrotoxicosis in the young adult in Basedow disease: report of 30 cases. Annales de Cardiologie et d Angéiologie 200049 161-167.

7 Osmak-Tizon L, Poussier M, Cottin Y \& Rochette L. Non-genomic actions of thyroid hormones: molecular aspects. Annales de Cardiologie et d'Angéiologie 2014107 207-211. (https://doi. org/10.1016/j.acvd.2014.02.001)

8 Razvi S, Jabbar A, Pingitore A, Danzi S, Biondi B, Klein I, Peeters R, Zaman A \& Iervasi G. Thyroid hormones and cardiovascular function and disease. Journal of the American College of Cardiology 201871 1781-1796. (https://doi.org/10.1016/j.jacc.2018.02.045) 
9 Choi YJ, Jang JH, Park SH, Oh SH \& Kph DK. Dilated cardiomyopathy with Graves' disease in a young child. Annals of Pediatric Endocrinology and Metabolism 201621 92-95. (https://doi. org/10.6065/apem.2016.21.2.92)

10 Bui PV, Zaveri SN \& Pierce JR. Sanguinous pericardial effusion and cardiac tamponade in the setting of Graves' disease: report of a case and review of previously reported cases. Case Reports in Medicine 2016 2016 9653412. (https://doi.org/10.1155/2016/9653412)

11 Weintraub RG, Semsarian C \& Macdonald P. Dilated cardiomyopathy. Lancet 2017390 400-414. (https://doi.org/10.1016/ S0140-6736(16)31713-5)

12 Muthukumar S, Sadacharan D, Ravikumar K, Mohanapriya G, Hussain Z \& Suresh RV. A prospective study on cardiovascular dysfunction in patients with hyperthyroidism and its reversal after surgical cure. World Journal of Surgery 201640 622-628. (https://doi. org/10.1007/s00268-015-3352-6)

13 Al-Ghamdi AS \& Aljohani N. Graves' thyrotoxicosis induced reversible cardiomyopathy: a case report. Clinical Medicine Insights: Case Reports 20136 47-50. (https://doi.org/10.4137/CCRep. S10534)

14 Chan PH, Hai J, Yeung CY, Lip GY, Lam KS, Tse HF \& Siu CW. Benefit of anticoagulation therapy in hyperthyroidism related atrial fibrillation. Clinical Cardiology 201538 476-482. (https://doi. org/10.1002/clc.22427)

15 Singer DE, Albers GW, Dalen JE, Fang MC, Go AS, Halperin JL, Lip GYH \& Manning WJ. Antithrombotic therapy in atrial fibrillation: American College of Chest Physicians evidence-based clinical practice guideline (8th edition). Chest 2008133 (Supplement 6) 546S-592S. (https://doi.org/10.1378/chest.08-0678)

16 Fuster V, Ryden LE, Cannom DS, Crijins HJ, Curtis AB, Ellenbogen KA, Halperin JE, Le Heuzey JY, Kay GN, Lowe JE, et al. ACC/AHA/ ESC 2006 guidelines for the management of patients with atrial fibrillation-executive summary: a report of the American College of Cardiology/American Heart Association Task Force on practice Guidelines and the European Society of Cardiology Committee for practice guidelines (writing committee to revise the 2001 guidelines for the management of patients with atrial fibrillation: developed in collaboration with the European Heart Rhythm Association and the Heart Rhythm Society. Journal of the American College of Cardiology 200648 854-906. (https://doi.org/10.1016/j.jacc.2006.07.009)

17 Gorenek B, Boriani G, Dan G-A, Fauchier L, Fenelon G, Huang H \& Kudaiberedieva G. European Heart Rhythm Association (EHRA) position paper on arrhythmia management and device therapies in endocrine disorders, endorsed by Asia Pacific Heart Rhythm Society (APHRS) and Latin American Heart Rhythm Society (LAHRS). EP Europace 201820 895-896. (https://doi.org/10.1093/europace/euy051)

18 Tsymbaliuk I, Unukovych D, Shvets N \& Dinets A. Cardiovascular complications secondary to Graves' disease: a prospective study from Ukraine. PLoS ONE. 201510 e0122388. (https://doi.org/10.1371/ journal.pone.0122388)

19 Gauthier JM, Mohamed HE, Noureldine SI, Nazari-Shafti TZ, Thethi TK \& Kandi E. Impact of thyroidectomy on cardiac manifestations of Graves' disease. Laryngoscope. 2016126 1256-1259. (https://doi.org/10.1002/lary.25687)

Received in final form 6 December 2019

Accepted 19 December 2019 